Paidéia, 2004, 14(29), 337-345

\title{
AS REPRESENTAÇÕES DE ESCOLARES DE BAIRROS PERIFÉRICOS SOBRE O ESPAÇO ONDE VIVEM ${ }^{1}$
}

\author{
Maria Esther Fernandes ${ }^{2}$ \\ Universidade Estadual Paulista de Franca
}

\begin{abstract}
Resumo: Este artigo faz parte de uma pesquisa mais ampla, desenvolvida no âmbito do Programa de Políticas Públicas da Fapesp, cujo objetivo fundamental foi compreender aspectos da vida e luta das camadas populares que habitam a periferia da cidade, através de sua fala. Nele, tentamos analisar as representações de escolares residentes em bairros periféricos de Ribeirão Preto-SP, sobre o espaço em que vivem. O material empírico foi levantado a partir de redações aplicadas aos alunos que cursavam as 4as e 5 as séries do $1^{\circ}$ grau, no $1^{\circ}$ semestre de 2000, da rede estadual e da rede municipal que atendem à clientela dos bairros compreendidos no universo da pesquisa: Jardim Progresso, Conjunto Habitacional Avelino Alves Palma e conjunto dos Jardins Anhanguera, Grajaúna, Novo Mundo e Zara, aí incluída a favela do Zara. Os textos revelam uma das faces mais cruéis da exclusão social-crianças privadas do acesso aos bens básicos da vida.
\end{abstract}

Palavras-chave: representações; crianças; bairro; exclusão social.

\section{SUBURBIAN SCHOLARLY REPRESENTATIONS OF THE SPACE THEY LIVE IN}

\begin{abstract}
This article is part of a broader research based and developed on the Fapesp Public Policy, and its fundamental goal was to understand, through their speech, aspects and struggles of life of people from popular social classes who dwell in the suburbs. In this research it was tried to analyze the scholarly representations about the space they live in (the periphery of Ribeirão Preto, State of São Paulo). The empiric material was raised from a written narration applied to students attending $4^{\text {th }}$ and $5^{\text {th }}$ grades in elementary degrees in the first semester of 2000, in public (state-run and county-run schools) which support the pupils of the suburbs referred in this research: Jardim Progresso, Conjunto Habitacional Avelino Palma, Jardim Anhanguera, Grajaúna, Novo Mundo and Zara including its slums. The texts reveal one of the most cruel aspects of children social exclusion deprived of access to basic life welfare.
\end{abstract}

Key-words: representations; children; borough (section or district); social exclusion.

Este artigo faz parte da pesquisa "As contradições do urbano na Califórnia Brasileira”, cujo objetivo fundamental foi compreender aspectos da vida e a luta das camadas populares que habitam a periferia da cidade, através de sua fala. À medida que a pesquisa foi se desenvolvendo, surgiu o desejo de apreender o ponto de vista das crianças com relação a esses bairros de periferia onde vivem, pedindo a elas que fizessem uma redação, cujo tema escolhido foi "Meu bairro".

As redações foram solicitadas aos alunos que cursavam a 4. ${ }^{\text {a } ~} 5 .^{\text {a }}$ séries do Ensino Fundamental em escolas da rede estadual e municipal que atendem à clientela de vários bairros, incluindo: Escola Estadual Getúlio Vargas; Escola Estadual Miguel Jorge e Escola Municipal Prof. José Rodini Luiz; Escolas Estaduais Glete de Alcântara e Professora Rosângela Basili.

Foram escolhidas essas séries porque as crianças teriam entre 10 e 12 anos, e tempo de escolaridade suficiente para que apresentassem domínio da escrita que permitisse a realização de uma redação própria ${ }^{3}$.

\footnotetext{
${ }^{1}$ Artigo recebido para publicação em 23/03/2004, aceito em 29/09/2004.

${ }^{2}$ Endereço para correspondência: Maria Esther Fernandes, Rua Alice Além Saad, 274 apto. 12, Nova Ribeirânia, Ribeirão Preto, SP, 14096-

570, E-mail: mesther@netsite.com.br
} 


\section{Maria Esther Fernandes}

\section{Método}

O procedimento adotado foi o seguinte: o pesquisador se apresentava ao diretor da escola, através de ofício encaminhado pela coordenadora do projeto, esclarecendo os objetivos da pesquisa e solicitando a permissão para que ele próprio aplicasse a redação nas salas de aula.

Em contato com os alunos, o pesquisador justificava o motivo de sua presença e solicitava às crianças colocarem no cabeçalho o título da redação, o nome da escola, sua idade, a série que estava cursando e o bairro onde residia, facultando a indicação de seu nome.

As redações foram aplicadas sob orientação e com a presença do pesquisador que permaneceu em sala de aula até o momento em que todas elas fossem recolhidas, cuidando para que nenhum elemento externo pudesse interferir no teor das redações. A utilização desse instrumento para a coleta de dados, ou seja, a aplicação de redações em escolas do Ensino Fundamental.

E, como as escolas atendem à clientela dos bairros vizinhos, encontra-se, em cada uma das salas, de 8 a 10 crianças do bairro incluído na pesquisa. Assim, foi preciso ampliar o universo anteriormente pretendido de duas salas de aula por escola, para quatro em cada uma delas.

Ao todo, foram recolhidas 306 redações dos alunos das 4. ${ }^{\text {a }}$ e $5 .^{\text {as }}$ séries de Escolas Públicas do Ensino Fundamental, assim distribuídas: 76 do Parque Ribeirão Preto, Jardim Maria da Graça e Branca Salles; 26 do Jardim Progresso; 90 do Conjunto Habitacional Avelino Alves Palma; e 102 dos Jardins Anhanguera, Grajaúna, Novo Mundo e Zara, aí incluída a Favela do Zara. ${ }^{4}$

A faixa etária variou de 9 a 12/13 anos. Como as redações foram aplicadas no $1 .^{\circ}$ semestre de 2000 (final de maio e início de junho), supõe-se que muitos desses alunos completariam 13 ou 14 anos, antes do final do ano.

\section{O que os textos revelam ${ }^{5}$}

"Meu bairro é uma coisa simples não é um bairro pobre e nem rico. Meu bairro não é um lugar de luxo ou de rico, é terra sem asfalto mas todo mundo o valoriza como moradia, todos vem de outro lugar o povo né, e todos são bemvindos, menos os bandidos." (Menino, 11 anos, 5. ${ }^{a}$ S., Jardim Progresso)

Para proceder à leitura das redações de crianças que habitam os bairros periféricos compreendidos no universo da pesquisa, foi necessário ler e reler, não apenas para penetrar o significado do que quiseram expressar, mas também para "decifrar" o que estava escrito, pois tanto os caracteres gráficos quanto a grafia evidenciam a precária alfabetização de grande parte dessas crianças. Alguns mal escrevem o nome. Outros, apenas poucas palavras. Certas redações são totalmente ilegíveis e outras estão em branco.

Ilustrando os textos, há desenhos de casas nos quais, por vezes, encontra-se uma flor do lado, mas um cadeado na porta; corações, tendo no centro a inscrição Vida sim, outros, Paz; pipas, jardins, flores, pássaros, estrelas. Uma menina ( 9 anos) traça um conjunto de casas, muito próximas, indicando a favela onde vive, o que lembra um texto de Ecléa Bosi (1979), em que ela leva a entrever a ausência de privacidade e o arranjo e rearranjo do espaço exíguo, ante o qual a extrema pobreza obriga a improvisar. No verso de um texto, em que a vida do bairro se circunscreve ao círculo de amigos, um menino (10 anos), do Jardim Zara, desenha um mapa no qual os pontos cardeais estão sinalizados pela figura e nome de cada amigo e o seu, indicando, talvez, o local de suas casas.

Embora a identificação do aluno fosse facultativa, muitos colocaram não apenas o seu nome, mas o dos pais, dos irmãos, dos amigos, da rua onde moram: querem dizer quem são.

$\mathrm{O}$ que teriam expressado se dominassem os signos da escrita? Na época do "aprendiz contínuo" com que armas lutarão?

\footnotetext{
${ }^{3}$ Em função da promoção automática, adotada pela legislação atual, certo número de crianças não pode participar da pesquisa, por não ter as competências necessárias.

${ }^{4}$ Uma observação se faz necessária: como os bairros da pesquisa fazem limite com outros bairros, em condições semelhantes ou muito próximas da realidade dos bairros pesquisados, achamos por bem incluir alguns textos de crianças deles provenientes, uma vez que refletem aspectos comuns à realidade vivenciada pelas crianças dos bairros-alvo desta pesquisa.

${ }^{5}$ Os textos aqui transcritos são apresentados sem nenhuma correção, mantendo a sua originalidade.
} 
“A exclusão é um todo.” A caligrafia e a alfabetização precária e tardia são algumas das marcas que distinguem alunos do Jardim Progresso e da Favela do Zara dos demais.

Os textos revelam uma das faces mais cruéis da exclusão social - crianças privadas do acesso aos bens básicos da vida.

Malgrado os limites de grafia, os textos são notadamente densos, eloqüentes, rompem, por assim dizer, os limites do código lingüístico. Revelam não apenas uma percepção aguda do social, apontando as feridas da sociedade, mas também sensibilidade, humanismo, solidariedade.

Impossível não se sentir tocado por esses relatos. Para alguns, o confronto precoce com a "vida severina" impõe-lhes, desde cedo, o exercício da resistência.

Uma menina (12 anos), cursando a 5. ${ }^{\text {a }}$ série, moradora do Jardim Progresso, inicia a redação dizendo que onde mora é "muito bom", a despeito da terra que tudo invade. Mesmo assim, revela gostar muito de lá, não só ela, mas todos os que lá vivem: "se não fosse ele (bairro), nós não estaríamos vivos mais como a vida nos mostra força e saúde graças adeus nós estamos vivos".

Outra menina (11 anos), moradora do Parque Ribeirão Preto, vê do bairro apenas a imagem negativa: "nunca vou conseguir sair da vida dura mesmo que consiga mudar de cidade". Queixa-se da violência, dos bandidos, do fato das crianças não brincarem sossegadas. Será a clara percepção dos limites impostos pela exclusão social que leva essa menina a afastar do seu horizonte uma vida melhor para o futuro? Que outros aspectos a fazem sentir o lado duro da vida?

Cá e lá, transparecem nos textos dessas crianças as preocupações com as desavenças entre os pais ou mesmo o sentimento da ausência de um deles, causada pela separação:

“(...) eu gostária que minha mãe e meu pai paracem de brigar." (Menina, 10 anos, $4 .^{a}$ s., Avelino Alves Palma)

"Eu moro ca minha vó e o meu pai minha mãe é separada do meu pai eu e meu irmõ tem saúdade da minha mãe." (Menina, 9 anos, $4 .^{a}$ S., Avelino Alves Palma)

"E eu gostaria de fazer uma mudança no meu bair- ro tirar as brigas. Meu sonho é ser dançarino minha vida é mais ou menos feliz (...) porque eu e minha familha estamos muito mal. Eu queria encontra meus pais felizes (...). Eu sou mais ou menos feliz." (Menino, 11 anos, 5. ${ }^{a}$ s., Avelino Alves Palma)

Será o desejo de pairar como pássaro no ar, acima das humanas contingências, que leva esse menino ao sonho de ser dançarino?

A familiaridade com a pesquisa de campo, ao mesmo tempo que concede a experiência para tratar com a realidade viva, adverte para a cautela na utilização dos instrumentos de pesquisa. Tenta-se ficar alerta aos limites da técnica e da própria observação.

Ferrarotti (1980) fala do receio de não estar suficientemente atento e sensível para compreender a fundo os textos biográficos.

Queiroz (1983), discorrendo sobre a complexidade da passagem do oral ao escrito (registro e transcrição da entrevista), descreve a impossibilidade de se recuperar o vivido em todas suas nuances: "o documento escrito, resultado destas duas fases, é uma pálida cópia da realidade, e é sobre esta pálida cópia que trabalha o pesquisador". (p.85).

Calvino (1997) refere-se aos limites e, ao mesmo tempo, ao esforço das palavras para darem conta, com possível precisão, do aspecto sensível das coisas, da densidade do mundo que nos rodeia. Segundo ele, a sensibilidade do poeta lhe permite aproximar-se da exatidão ao fazer uso da linguagem: "penso em William Carlos Williams descrevendo tão minuciosamente as folhas do ciclâmen, o que faz com que a flor tome forma e desabroche nas páginas em que a descreve, conseguindo dar à poesia a mesma leveza da planta”.

É o leitor quem confere vida aos "signos mortos da escrita”. É o pesquisador quem opera a intermediação entre documento e realidade. É seu olhar que irá direcionar cortes, recortes, montagem, fragmentando, recompondo e construindo um novo texto, a partir da seleção temática. A tentativa é sempre descobrir o que se oculta sob o imediatismo da evidência empírica, de modo a compreender mais profundamente o sentido dos dados.

Buscou-se, a cada releitura das redações, apreender não apenas os temas dominantes mas, tam- 


\section{Maria Esther Fernandes}

bém, o detalhe pertinente, na tentativa de oferecer ao leitor a possibilidade de entrever o manancial presente nos textos dessas crianças.

De início, procedeu-se à análise das redações, bairro a bairro. Foi essa a sistemática adotada para uma primeira leitura das redações. À medida que ia sendo feita a seleção temática, começou-se a perceber que, embora cada um dos bairros guardasse sua especificidade, poder-se-ia, após realizada a etapa de decomposição dos temas, bairro a bairro, agrupar as “famílias" de temas para abordá-los de forma conjunta. Isso porque alguns deles, como a violência, apresentam elementos comuns, independentemente da localização do bairro. Outros, como carências, já trazem especificidades. No todo, as peculiaridades de cada família temática assumiriam maior relevo, apontando a singularidade de cada bairro.

Os temas seguintes constituem o denominador comum, perpassando a maioria das redações: violência, seguido de carências (que também é violência) e, depois, equivalendo-se, na freqüência e ordem de abordagem, família, amigos, brincadeiras, vizinhança.

O tema constante que se sobressai entre os demais é o da "violência". No Avelino Alves Palma, de um total de 90 alunos, apenas seis não se referem à violência. No Parque Ribeirão Preto, Jardim Progresso, Jardim Maria da Graça e Branca Salles, de um total de 102, 20 não se referem à violência. Nos Jardins Anhangüera, Grajaúna, Novo Mundo e Zara, de um total de 114 redações, as referências à violência se concentram no Jardim Zara. No Jardim Novo Mundo, entre 19 redações, apenas 1 se refere à violência. No Zara, das 58 redações, 4 em branco e 3 ilegíveis (crianças de 10 a 12 anos que mal escrevem o nome), há 37 referências à violência. Entre elas, dez atribuem a violência à presença da Favela do Zara.

Mas essa violência presente nas redações também tem diversas faces, assim como os perigos que habitam o bairro.

\section{Análise dos dados}

Na redação de um garoto (10 anos), morador do Avelino Alves Palma, em 23 linhas a palavra violência aparece oito vezes. Ele narra que, quando jogava bola na rua, num sábado, presenciou a morte de um rapaz (20 anos), vítima de uma bala perdida, en- quanto aguardava a namorada.

De modo geral, violência e carência aparecem juntas:

"O meu bairro é muito violento. Ele não é muinto movimentado. O meu bairro é muito bom, mas lá há muitas mortes. O meu bairro para ser melhor é preciso cuidar dos bueros, limpeza, menos violência e ele é bem sujo e ele precisa de mais arvores e educação merenda na escola e atendimentos nos Postos de Saúde e mais livros para as crianças estudar e um bom encino e dentistas." (Menino, 11 anos, 4. ${ }^{a}$ s., Jardim Progresso)

Muitas vezes, a referência à violência vem acompanhada do desejo de paz. No Avelino Alves Palma, onde a violência alcança altos índices, em função do narcotráfico, em alguns textos fica muito clara a divisão dos mundos: o das drogas, dos traficantes, dos malandros, dos bandidos e o das pessoas boas.

"O meu bairro é muito legal. Mas se eu pudesse mudar ele, ia ser muito legal não mais tinha nada de mal. Porque ia ser um bairro limpo e maravilhoso, não tinha mais briga, guerra (ele se refere à guerra entre as gangues do Quintino Facci II e do Avelino), nem luta e o mundo ia melhorar." (Menino, 10 anos, 4. $^{a}$ s., Avelino Alves Palma)

"Meu bairro e tão violênto, queria que o mundo não tivesse violência assim seria bem melhor. $O$ meu bairro tem violência de dia e tem violência de noite. Se o mundo não tivesse violência, tudo seria melhor, demoraria para alguém morrer e todos se gostariam um ao outro todo mundo torçe para que seja assim. No meu bairro só conheço as pessoas da minha rua. Um dia talvez o mundo consiga mudar.” (Menina, 4. ${ }^{a}$ s., Avelino Alves Palma)

"Não gosto de pessoas ruins e mas, só gosto de pessoas que fazem o bem e o bom." (Menino, 10 anos, $4 .{ }^{a}$ S., Avelino Alves Palma)

“(...) meu bairo ele é cheio de malandros eu não gosto deles porque são chatos fumão craque $e$ cocaina e droga, dão tiro em gente inosente, matão qriansas e mulher." (Menino, 10 anos, $4 .{ }^{a}$ s., Avelino Alves Palma)

“No meu bairo e muito violeto eu queria quetivese 
paz no mundo inteiro (...) que a paz e boua, eu queria o mundo de jente boua." (Menino, 10 anos, 4. ${ }^{a}$ s., Avelino Alves Palma)

Muitas vezes, o receio da violência os leva ao desejo de mudarem de cidade ou mesmo para a zona rural para fugirem dela.(...) "eu queria mudar dessa cidade para outro lugar que eu queria viver em paz." (...) "Eu tenho medo a noite. Na minha rua so ten gente que reclama. Eu queria morar numa fazenda."

Em outros textos, o reconhecimento de que a violência não está circunscrita a um local, mas em toda parte, não havendo como dela fugir:

"Eu não quero mudar de Bairro porque se for por causa da violência tá em todo lugar nesse Bairro e nos outro." (Menina, 11 anos, $5 .^{a}$ S., Parque Ribeirão Preto)

"Nem um Bairro não é perfeito porque todos os Bairros é muito violento." (Menina, 10 anos, $4{ }^{a}$ s., Jardim Maria da Graça)

Às vezes, a consciência de que a violência constitui ameaça para os familiares indefesos (mãe e irmão menor) leva ao desejo de protegê-los.

"Meu bairro é bom alem de ser violento o nome dele é Branca Sales (...) e bom mas perigoso, e tan perigoso que tenho vontade de comprar vario cachorro para proteger meu irmãzinho e minha mãe." (Menino, 11 anos, $4{ }^{a}$ s., Branca Salles)

"Eu moro no Jardim Progresso lá tem bar e também tão fazendo um mercado, mais tem muito Bandido e toda noite tem teroteio Eu fico com muito medo um dia ausentaram meu tio, tem gente que diz que não e perigoso tem gente que diz e sim perigoso Eu acho que é perigoso."(Menino, 10 anos, $4 .{ }^{a}$ s., Jardim Progresso)

No texto de uma menina (10 anos), evidencia-se a idéia de que a violência não se limita à ação dos bandidos. As enchentes na cidade grande, que levam os pobres a perderem suas casas, também são violência: "nós vé o jornal e fica apavorada com as mortes estrupos pessoas queimada pessoas esfaqueadas mas não é só aqui como lá em São Paulo casas indo pela chuva" (5. ${ }^{\mathrm{a}}$ s., Parque Ribeirão Preto).

Embora se saiba que os destaques dos jornais televisivos carreguem no relato das violências, os estudos sobre comunicação de massa ensinam que é o quadro de referência do receptor que confere relevo a este ou àquele aspecto do noticiário. $\mathrm{O}$ que teria levado essa menina, entre o leque diferenciado de informações do telejornal, a selecionar eventos e situações ligados à violência? Foi seu universo de vida o subsolo dessa seleção?

Ecléa Bosi (1972), analisando os relatos de jornais, feitos por jovens operárias de uma fábrica da zona leste de São Paulo, onde se destacam a violência cometida contra a mulher e a criança, refere-se ao "vitimismo feminino", indagando sobre seu significado em termos sociais. E conclui que tais relatos espelham o sofrimento milenar da criança pobre que, obrigada a vender, dia a dia, sua força de trabalho, estará impedida de desenvolver seus talentos.

\section{Carências}

Jardim Progresso: um lugar para viver é o bastante

Um dado que salta aos olhos, quando se vêem os textos das crianças e pré-adolescentes do Jardim Progresso é que, malgrado as carências de toda ordem (lama e poeira em decorrência da ausência de pavimentação das ruas, falta de água, de $l u z^{7}$ ), a identificação com o bairro é bastante forte. Frases como "é muito bom", "lá tem muitas coisas legais, eu adoro lá", são bastante freqüentes.

Sempre presente nos textos o sentido do coletivo "árvores para dar sombra para todos nós”, o desejo de paz não apenas para sua rua, seu bairro, sua cidade, mas "para o mundo inteiro por vários Ribeirão Preto". O bairro acolhendo não apenas a eles, sua família, mas "o povo né todos são bemvindos, menos os bandidos".

\footnotetext{
${ }^{6}$ Recentemente, a expressão "aprendiz contínuo" ou "aprendiz permanente" vem sendo utilizada no sentido da busca de conhecimento e informação não mais se limitar aos quadros da educação formal. Diante das crescentes exigências do mercado e da sociedade globalizada, o autodidatismo tornou-se imperativo na vida de todos nós, como condição básica de cidadania.

${ }^{7}$ As melhorias em infra-estrutura no Jardim Progresso tiveram início no $1 .{ }^{\circ}$ semestre de 2001. Portanto, como as redações foram aplicadas no $1 .{ }^{\circ}$ semestre de 2000, as considerações seguintes referem-se à percepção das crianças antes do início das obras.
} 


\section{Maria Esther Fernandes}

Em face do cenário do bairro onde vive, em meio a severas privações, o menino afirma: "não é um bairro pobre e nem rico". Será a consciência de que existem outros ainda mais pobres, para os quais "ponte não há", como revela o texto de um menino (12 anos), morador de uma casa de Cohab?.

"Eu vi da Baia, sou baiano eu tenho orgulho de morar onde eu moro sabe porque eu tenho orgulho porque tem gente presizando de uma casa abandonado (...) vem atraz de papelam para por no chão para seus filho deita eu tenho orgulho do meu bairro e da minha casa." (Menino, 12 anos, 5. ${ }^{a}$ s., Branca Salles)

Os textos revelam um dado fundamental: diante dos obstáculos impostos pela ausência de infraestrutura (a terra, a poeira, a lama), a casa, o bairro não são tão somente o teto que abriga, que acolhe, que protege, são a expressão dos mínimos vitais, abaixo dos quais a sobrevivência está ameaçada. Não importa que seja um lugar de "terra sem asfalto" e não um lugar de "luxo ou de rico".

"meu bairro não tem rua, tem rua mas só tem barro", "é terra sem asfalto", "não tem luz no poste e também não tem esgoto (...) não tem água nas casas”, há sempre a valorização do espaço “mas todo mundo o valoriza como moradia”, "mas tá tudo bem lá, cada um de nóis tem suas próprias casa”, "porque tem gente precisando de uma casa, abandonado", "se não fosse ele (o bairro), nós não estaríamos vivos".

O acostumar-se à lama, ao barro, nos dias de chuva, e à poeira, na estiagem, não soa como imposição, mas como decorrência natural ante a ausência de alternativas, a premência de um lugar para viver: "tem muita terra que nós não agüentamos nem ficar lá direito de tanta terra que tem, mas eu gosto dele mesmo assim (...) eu não gosto de ficar falando muito dele porque eu vou precisar muito dele"assim como não lhe é penoso o adaptar-se, desde muito cedo, à precariedade, ao alojar-se, não importa como.

Ou, então, sentir-se privilegiado, enaltecido, pelo fato de possuir um bem, do qual outros são privados. "Eu vi da Baia, sou baiano eu tenho orgulho de morar onde eu moro sabe porque eu tenho orgu- lho porque tem gente presizando de uma casa abandonado."

Na constatação de que o lugar onde vive "não é um lugar de luxo ou de rico", há a idéia de que existem distâncias bem marcadas, limites bem definidos entre os dois mundos. O menino que confessa se envergonhar de residir num bairro tão pobre, toma como referência o outro - espelho através do qual ele se enxerga como menos aquinhoado.

É contemplando-se no olhar que os outros the dirigem que o indivíduo constrói o seu "si-mesmo". Cooley (1971) denomina esse mecanismo de "looking glass self”, ou seja, o "si-mesmo" refletido no espelho do olhar do outro. É em contato com o outro que aprendemos a nos perceber enquanto pessoa, e essa consciência existencial tem raízes profundamente sociais.(p.30).

\section{Sem teto: o estigma das "classes perigosas"}

Nos textos das crianças do Jardim Progresso (mais conhecido como sem-teto), muitas vezes se encontra a frase: "Eu moro no sem-teto". Que sentimento deve tomar conta de uma criança ao dizer que mora no "sem-teto”? Que significado ela própria atribui ao fato de viver nesse bairro?

De qualquer maneira, pesa sobre ela uma discriminação, que não é proveniente tão-somente de outras classes sociais, mas de alguém oriundo da mesma camada que a sua. Verifica-se no texto de um menino que mora no Branca Salles, bairro próximo ao Jardim Progresso e tão violento quanto este, a seguinte referência:

"O meu bairro ero muito Bom. Ero silenciozo e legal eu adorava muito o meu bairro. Mais agora a prefeitura construiu o bairro sem teto e o Brancco Sales agora é muito ruim por que agora quase todo dia sai tiro aqui no Parque Ribeirão (...) daqui alguns dias eu vou me muldar para o bairro Marquesi." (Menino, 10 anos, $4 .{ }^{a}$ S., Branca Salles)

Uma moradora do Jardim Progresso que freqüenta a mesma escola e estuda na mesma sala de aula do menino que redigiu o texto acima, a queixa à discriminação proveniente dos colegas:

"O meu bairro chama Jardim Progresso. Eu acho ele muito legal, eu gosto muito dele apesar das 
coisas que andam acontecendo. As pessoas acham lá perigoso por causa dos assaltos e mortes que acontece lá. Tem meninos e meninas que ficam mechendo comigo so por que eu moro no Jardim Progresso. Mas eu acho que onde a pessoa mora não vai torná-la perigosa. Nós temos que ver as pessoas do jeito que elas são, não por onde ela mora." (Menina, 11 anos, 5. ${ }^{a}$ s., Jardim Progresso)

Essa discriminação que pesa sobre as pessoas que vivem em áreas “perigosas” é corroborada pelo depoimento de uma senhora, entrevistada em agosto/ 1999, que reside no mesmo local. Na ocasião, ela relatou que, em função de uma enfermidade do marido que acarretava altos gastos com medicamentos, não mais puderam pagar o aluguel em São Bernardo, onde viviam. A alternativa para fazer frente aos gastos foi vir para Ribeirão onde têm uma filha que lhes fornece a cesta básica. A informante relata que, indagada por uma conhecida sobre o local onde estava morando, quando apontou o Horto, chegou a ficar "meio acanhada" - "Lá, no meio dos bandidos?”. A senhora se explica para o pesquisador: "Mas aqui tem muita gente boa que trabalha. A gente veio pra cá porque não tinha outro recurso".

Lopes (1997), num estudo realizado sobre trabalhadores sem-teto em que um dos objetivos foi investigar como se revelam as vivências desse trabalhador na "luta pela casa" e na "luta pela inserção social na cidade", analisando o que ela denomina "ética do habitar", concebe o conceito e a instituição "família" como sinônimo de "casa" e aí destaca o valor cultural de família nuclear, bastante arraigado entre as classes trabalhadoras do país, dificilmente vivenciado pelos indivíduos que por ela entrevistados. Assim, muitos foram obrigados a buscar, na ocupação urbana, alternativa para viver a experiência da família nuclear que não conseguiram por não terem condições de pagar o aluguel.

Segundo ela, existe uma dimensão subjetiva, emocional, associada ao "teto", tanto assim que, desde muito cedo, surgem, nos desenhos infantis, a “casa”, símbolo do desejo constante dessa "casa” cujo sentido mais profundo extrapola a mera função de “acolher corpos”. Nas palavras da socióloga:

... a busca constante de uma "casa" ou "teto" se traduz em símbolos de identidades individuais e sociais, que se manifestam em questões humanas essenciais (...). Por esta razão é tão comum, e quase sempre inconsciente, o desejo constante de uma "casa" durante toda a vida, desde os primeiros desenhos infantis. $O$ indivíduo que nunca alcançar uma casa-mercadoria, mesmo assim "habitará" alguma "casa" de sua imaginação, que nunca será a mesma ao longo da vida, modificando-se continuamente com as mudanças do próprio sujeito imaginante. Esta é uma das questões centrais para o entendimento dos movimentos sociais por habitação, muito embora pouco reconhecida socialmente, seja no plano do conhecimento, seja nos processos de organização política da sociedade civil ou no plano das políticas públicas”. (Lopes, 2001, p.13)

\section{Considerações Finais}

Muitas vezes, ao abordarem a questão da violência, fica claro que não são apenas os homicídios, assaltos e roubos que constituem violência. As agressões contra os idosos, a fome, o desamparo das crianças, o injusto salário-mínimo, os irrisórios proventos dos aposentados também são violência.

“(...) porque eu gostaria que no futuro todos nós crianças, velos e adultos tivesem amor, carinho, moradia e escolas e uma família unida porque hoje porque nos vemos no nosso bairo e cidades e país essa des união poriso esta dese geito com guera e violencia por todo lugar onde quer que nos pasamos éssa onda de violencia de pai contra velhos e velhos contra pais, criança morrendo de frio e fome se drogando na rua, guerras de bairro contra bairro eu gostaria que tudo (tivesse) um fim num futuro bem próximo como o amanhã." (Sem indicação de idade e sexo)

\footnotetext{
"Quando eu crescer eu vou querer ser prefeita, os prefeitos e prefeitas de hoje não fazem nada. Se eu for prefeita a primeira coisa que eu ia realizar em uma cidade era tampar os buracos das ruas $e$ ia dar empregos para as pessoas de qualquer idade $e$ iria dar mais seguranças. Eu iria mandar os policiais prenderem os verdadeiros bandidos e não os inocentes, e que os ladrões cumpria os anos de prisão e que teria mais policiais nas cadeias para não haver rebeliões, e que policiais ficassem na saída e na entrada da escola, porque na minha não tem. Se eu for prefeita eu iria aumentar o salário mínimo e a aposentadoria dos idosos. Só isso
} 


\section{Maria Esther Fernandes}

que eu queria que acontecia nessa cidade." (Menina, 10 anos, 4. ${ }^{a}$ s., Avelino Alves Palma) (Grifo nosso)

“(...) Também gostaria que na rua descem todos bem, seria muito bom. Já pensaram se fosse muito legal, todos se descem bem e apertacem a mão $e$ dizia: - Oi vizinho como vai você vai bem, espero que seja um bom dia para você, no trabalho e em casa." (4. ${ }^{a}$ s., Avelino Alves Palma) (Grifo nosso)

Num texto em que toda a redação se encontra no condicional, uma menina (10 anos), residente no Parque Ribeirão Preto, ao apontar as carências do seu bairro, entre elas a morosidade do atendimento médico nos postos de saúde, decorrência, segundo ela, do escasso número de médicos para as demandas do bairro onde reside, denunciando a ineficácia dos serviços públicos, manifesta o desejo de que os professores tenham salários mais dignos e, também, de políticas sociais que atendam às reais necessidades dos expropriados.

“(...) gostaria que ajudava as pessoas necessitadas. Eu também gostaria que tinha mais médicos nos posto de saúde porque tem poucos medicos $e$ se quizer consota (consulta) tem que marcar conçota (consulta) e demora um mês para chamar ou mais. E também gostaria ametava mais o salarios dos professores. E também gostaria e não tinha mais violensia." (Menina, 10 anos, $4 .^{a}$ s., Parque Ribeirão Preto)

$\mathrm{Na}$ raiz de seus anseios, transparecem, limpidamente e com toda força - tal broto salta da terra -, seus valores mais caros. Entre eles, a preocupação com o próximo, a compaixão pelos mais necessitados, o desejo de uma sociedade mais humana e mais justa, em que a fome, a violência, o desemprego, as injustiças e o desamparo da infância e da velhice teriam um fim, não em um futuro distante, mas no amanhã: “... eu gostaria que tudo tivesse um fim (ele se refere às injustiças sociais e à violência) num futuro bem próximo como o amanhã".

Esta frase que se encontra no texto de abertura deste tópico, dado o caráter de imediatez do projeto almejado - o amanhã, fez-me lembrar o poeta israelense Jehuda Amichai que, aos 76 anos, escreveu nos seus últimos dias de vida:
(...) eu, que ainda estou vivo, digo:

que eu possa ter paz no que tenho de vida.

eu quero paz agora mesmo, enquanto ainda estou vivo.

não quero esperar como aquele piedoso que almejava

uma perna do trono de outro do Paraíso. Quero uma cadeira

de quatro pernas, aqui mesmo, uma cadeira simples de madeira.

Quero o resto de minha paz agora. (2000)

O projeto da sociedade que as crianças almejam é abrangente, não é para poucos, mas universal: “(...) porque eu gostaria que no futuro, todos nós, crianças, velhos e adultos tivessem amor, carinho, moradia e escolas”; “(...) eu ia dar empregos para as pessoas de qualquer idade (...) aumentar o salário mínimo e a aposentadoria dos idosos”; “(...) faria com que todas as crianças fossem para a escola. E assim dividiríamos nossas coisas com as pessoas que precisam”; “(...) gostaria que o mundo tivesse pelo menos um dia de paz, onde as pessoas pudessem falar o que pensava, fazer novos amigos, tentar entender e compreender as pessoas".

Um "sobrevôo" no teor das redações, apontanos uma das faces mais cruéis da violência que recai sobre essas crianças, violência que não se restringe ao contato precoce com a arma, a droga, a morte, os tiroteios, a degradação do espaço público. A violência maior reside no fato de, desde muito cedo, serem obrigadas ao confronto com a realidade. Escrevem como crianças, mas as opiniões são de adultos.

Para finalizar, vale destacar passagens do diário de campo que o olhar arguto da fotógrafa Maria Dolores Aybar Ramírez registrou sobre crianças do Zara e do Jardim Progresso.

O menino pequeno, muito pequeno, diz: “- Oi, tia” e sorri apenas,com sorriso curto de pouco mais de três anos. Ele olha muito, fixo, bonito, com seu rosto limpo e seus olhos tristes. Eu avanço. Por trás da máquina. Há algo no ar, além do ar que gruda às narinas. Uma ameaça invisível e escura e um "oi”, ecoando, como um som de vento impossível. O homem que não vejo esbraveja no barraco da esquerda, no lar do menino triste, talvez, de outro menino. Há algo aberrante nesse labirinto de madeiras 
ocres, papelão e arames - alguns bem farpados latões e ferros. Há na geometria do Zara, um arabesco que apaga saídas e atrai para o centro. Existe também o horror, o terror ao vazio, o desafio palpitante da linha sem retas nem prumos, do acaso triste que obriga a olhar para baixo, para dentro. O olhar dos meninos, o olhar das meninas, o olhar das mulheres. O olhar dos homens? Onde eles se escondem?

$$
\text { (...) }
$$

Um outro menino, de um outro Jardim, chamado Progresso, com rosto de homem de uns oito aninhos, correndo, puxando, fitando, gritou-me:

- O que você fotografou lá em cima?

- Lá em cima? Onde?

- Na casa aqui da rua.

- Ah! Nessa casa! Achei bonita essa casa.

- É minha casa!

- E o que tem de mais bonito na sua casa?

$-\ldots E u !$

O menino do Jardim Progresso dizia “eu” e dizia "minha" e sorria comprido e viril, como fazem homens pobres ainda crianças, que carregam outros homens, outros nomes, na memória.

Os meninos da favela do Zara choram muito pouco e riem muito pouco. Nenhum choro perturba o ar que estagna quente sob as telhas "eternit" eternamente baixas, matando os horizontes.

$$
\text { (...) }
$$

E num lampejo, o instantâneo de um olhar que sonha e mora ali. E noutro, a faísca de um olhar que odeia e mora ali.

Todos com poucas perguntas. Os meninos do Zara parecem cansados de revirar sacolas à procura de respostas.

A favela ecoa com seu barulhinho surdo, como um turbilhão mal fixado, com revelador vencido, nos papéis fosco-fugazes. Não cabe o retoque.

\section{Referências Bibliográficas}

Amichai, J. (2000). Folha de S. Paulo, São Paulo: 22 outubro Mais - Contracapa.

Bosi, E. (1972). Cultura de Massa e cultura popular: leituras de operárias. Rio de Janeiro: Vozes.

Bosi, E. (1979). Problemas ligados à cultura das classes pobres. Em E.Valle \& J. J. Queiroz, (orgs.). A cultura do povo. São Paulo: Cortez \&
Moraes/Edusp.

Calvino, I. (1997). Seis propostas para o próximo milênio. São Paulo: Companhia das Letras.

Cooley, C. (1971). Human Nature and Social Order Em G. Rocher, Sociologia Geral 2. Lisboa: Presença.

Ferrarotti, F. (1980). Les biographies comme instrument analytique et interprétatif. Cahiers Internationaux de Sociologie. Numéro Special. Histoire de vie et vie social. Paris, 69, 223-245.

Lopes, D. A. (2001). Casa, despejo e cultura do habitar. Cadernos CERU. São Paulo.

Lopes, D. A.(1997). Trabalhador sem teto e habitação provisória: vivência acerca dos processos de perda de memória urbana. Tese de Doutorado, São Paulo: FFLCH-USP.

Pagnan, R.. (2001). Ribeirão deixa 22 mil à margem do ensino. Folha de S. Paulo, São Paulo, 2 ago.

Queiroz, M. I. P. (1983). Das entrevistas e sua transcrição. Em Variações sobre a técnica de gravador no registro da informação viva. São Paulo: Ceru/FFLCH-USP, Coleção Textos. 